\title{
New Mixed Equilibrium Problems and Iterative Algorithms for Fixed Point Problems in Banach Spaces
}

\author{
Minjiang Chen, ${ }^{1}$ Jianmin Song, ${ }^{1}$ and Shenghua Wang ${ }^{2}$ \\ ${ }^{1}$ School of Mathematics and Sciences, Shijiazhuang University of Economics, Shijiazhuang 050031, China \\ ${ }^{2}$ Department of Mathematics and Physics, North China Electric Power University, Baoding 071003, China \\ Correspondence should be addressed to Shenghua Wang; sheng-huawang@hotmail.com
}

Received 30 October 2013; Accepted 16 December 2013; Published 9 January 2014

Academic Editor: Li Wei

Copyright (c) 2014 Minjiang Chen et al. This is an open access article distributed under the Creative Commons Attribution License, which permits unrestricted use, distribution, and reproduction in any medium, provided the original work is properly cited.

\begin{abstract}
We first introduce a new mixed equilibrium problem with a relaxed monotone mapping in Banach spaces and prove the existence of solutions of the equilibrium problem. Then we introduce a new iterative algorithm for finding a common element of the set of solutions of the equilibrium problem and the set of fixed points of a quasi- $\phi$-nonexpansive mapping and prove some strong convergence theorems of the iteration. Our results extend and improve the corresponding ones given by Wang et al., Takahashi and Zembayashi, and some others.
\end{abstract}

\section{Introduction}

Let $E$ be a Banach space with the dual space $E^{*}$ and let $K$ be a nonempty closed convex subset of $E$. Let $\Theta$ be a bifunction from $K \times K$ to $\mathbb{R}$, where $\mathbb{R}$ denotes the set of numbers. The equilibrium problem is to find $x^{*} \in K$ such that

$$
\Theta\left(x^{*}, y\right) \geq 0, \quad \forall y \in K .
$$

The set of solutions of the above equilibrium problem is denoted by $\mathrm{EP}(\Theta)$.

In order to solve the equilibrium problem, the bifunction $\Theta$ is usually to be assumed that following conditions are satisfied:

(A1) $\Theta(x, x)=0$ for all $x \in K$;

(A2) $\Theta$ is monotone; that is, $\Theta(x, y)+\Theta(y, x) \leq 0$ for all $x, y \in K$

(A3) for all $x, y, z \in K$,

$$
\limsup _{t \downarrow 0} \Theta(t z+(1-t) x, y) \leq \Theta(x, y)
$$

(A4) for all $x \in K, \Theta(x, \cdot)$ is convex and lower semicontinuous.
Recently, Takahashi and Zembayashi [1] extended the equilibrium problems and fixed point problems from Hilbert spaces to Banach spaces. More precisely, they gave the following iterative scheme:

$$
\begin{gathered}
x_{0}=x \in K, \\
y_{n}=J^{-1}\left(\alpha_{n} J x_{n}+\left(1-\alpha_{n}\right) J S x_{n}\right),
\end{gathered}
$$

$u_{n} \in K$ such that $\Theta\left(u_{n}, y\right)$

$$
\begin{gathered}
+\frac{1}{r_{n}}\left\langle y-u_{n}, J u_{n}-J y_{n}\right\rangle \geq 0, \quad \forall y \in K, \\
H_{n}=\left\{z \in K: \phi\left(z, u_{n}\right) \leq \phi\left(z, x_{n}\right)\right\}, \\
W_{n}=\left\{z \in K:\left\langle x_{n}-z, J x-J x_{n}\right\rangle \geq 0\right\}, \\
x_{n+1}=\Pi_{H_{n} \cap W_{n}} x, \quad \forall n \geq 0,
\end{gathered}
$$

where $S$ is a relatively nonexpansive mapping from $K$ into itself such that $F(S) \cap \operatorname{EP}(\Theta) \neq \emptyset, J$ is the duality mapping on $E$, and $\left\{\alpha_{n}\right\} \subset[0,1]$ satisfies $\liminf _{n \rightarrow \infty} \alpha_{n}\left(1-\alpha_{n}\right)>$ 0 and $\left\{r_{n}\right\} \subset[a, \infty)$ for some $a>0$. They proved that the sequence $\left\{x_{n}\right\}$ generated by (3) converges strongly to $\Pi_{F(S) \cap \mathrm{EP}(\Theta)} x$, where $\Pi_{F(S) \cap \mathrm{EP}(\Theta)}$ is the generalized projection of $E$ onto $F(S) \cap \mathrm{EP}(\Theta)$. 
Very recently, Qin et al. [2] introduced the following hybrid algorithm to solve the equilibrium problems and fixed point problems for quasi- $\phi$-nonexpansive mappings in a uniformly convex and uniformly smooth Banach space $E$ with a nonempty closed convex subset $K$ of $E$ :

$$
\begin{gathered}
x_{0} \in E \text { chosen arbitrarily, } \\
C_{1}=K, \\
x_{1}=\Pi_{C_{1}} x_{0}, \\
y_{n}=J^{-1}\left(\alpha_{n} J x_{n}+\beta_{n} J T x_{n}+\gamma_{n} J S x_{n}\right), \\
u_{n} \in K \text { such that } \Theta\left(u_{n}, y\right) \\
+\frac{1}{r_{n}}\left\langle y-u_{n}, J u_{n}-J y_{n}\right\rangle \geq 0, \quad \forall y \in K, \\
C_{n+1}=\left\{z \in C_{n}: \phi\left(z, u_{n}\right) \leq \phi\left(z, x_{n}\right)\right\}, \\
x_{n+1}=\Pi_{C_{n+1}} x_{0}, \quad \forall n \geq 0,
\end{gathered}
$$

where $T$ and $S$ are two quasi- $\phi$-nonexpansive mappings from $K$ into itself such that $F=F(T) \cap F(S) \cap \operatorname{EP}(\Theta) \neq \emptyset,\left\{\alpha_{n}\right\},\left\{\beta_{n}\right\}$, and $\left\{\gamma_{n}\right\}$ are three sequences in $[0,1]$ satisfying some certain conditions. They proved that the sequence $\left\{x_{n}\right\}$ generated by (4) converges strongly to $\Pi_{F} x_{0}$, where $\Pi_{F}$ is the generalized projection of $E$ onto $F$.

In [3], Fang and Huang introduced a concept called a relaxed $\eta$ - $\alpha$-monotone mapping.

A mapping $A: K \rightarrow E^{*}$ is said to be relaxed $\eta$ - $\alpha$-monotone if there exist a mapping $\eta: K \times K \rightarrow E$ and a function $\alpha: E \rightarrow \mathbb{R}$ with $\alpha(t z)=t^{p} \alpha(z)$ for all $t>0$ and $z \in E$, where $p>1$ is a constant, such that

$$
\langle A x-A y, \eta(x, y)\rangle \geq \alpha(x-y), \quad \forall x, y \in K .
$$

Especially, if $\eta(x, y)=x-y$ for all $x, y \in K$ and $\alpha(z)=$ $\kappa\|z\|^{p}$, where $p>1$ and $\kappa>1$ are two constants, then $A$ is said to be $p$-monotone (see, e.g., [4-6]). They proved that, under some suitable assumptions, the following variational inequality is solvable: find $x \in K$ such that

$$
\langle A x, \eta(y, x)\rangle+f(y)-f(x) \geq 0, \quad \forall y \in K,
$$

where $f$ is a function from $K$ to $\mathbb{R} \cup\{\infty\}$. They also proved that the variational inequality (6) is equivalent to the following: find $x \in K$ such that

$$
\langle A y, \eta(y, x)\rangle+f(y)-f(x) \geq \alpha(y-x), \quad \forall y \in K .
$$

In this paper, let us denote the set of solutions of the variational inequality (6) or (7) by $\Omega$.

It is worthy to notice that it is possible that $\Omega$ is a singleton set, includes the finite elements or infinite elements. To show this, we see the following example.

Example 1. Let $E=\mathbb{R} \times \mathbb{R}$ and $K=[0,1] \times[0,1]$. Define the mappings $A: K \rightarrow E^{*}$ by $A\left(x_{1}, x_{2}\right)=\left(x_{1}, x_{2}\right)$ for all $\left(x_{1}, x_{2}\right) \in K, \alpha: E \rightarrow \mathbb{R}$ by $\alpha\left(\left(x_{1}, x_{2}\right)\right)=3 x_{1}^{2}+3 x_{2}^{2}$ for all $\left(x_{1}, x_{2}\right) \in E$, and $\eta: K \times K \rightarrow E$ by $\eta\left(\left(x_{1}, x_{2}\right),\left(y_{1}, y_{2}\right)\right)=$ $\left(4\left(x_{1}-y_{1}\right), 4\left(x_{2}-y_{2}\right)\right)$ for all $\left(x_{1}, x_{2}\right) \times\left(y_{1}, y_{2}\right) \in K \times K$. Then the mapping $A$ is a relaxed $\eta$ - $\alpha$-monotone mapping. In fact, for all $x=\left(x_{1}, x_{2}\right), y=\left(y_{1}, y_{2}\right) \in K$, we have

$$
\begin{aligned}
\langle A x & -A y, \eta(x, y)\rangle \\
& =\left\langle\left(x_{1}-y_{1}, x_{2}-y_{2}\right),\left(4\left(x_{1}-y_{1}\right), 4\left(x_{2}-y_{2}\right)\right)\right\rangle \\
& =16\left[\left(x_{1}-y_{1}\right)^{2}+\left(x_{2}-y_{2}\right)^{2}\right] \\
& \geq 3\left[\left(x_{1}-y_{1}\right)^{2}+\left(x_{2}-y_{2}\right)^{2}\right] \\
& =\alpha(x-y) .
\end{aligned}
$$

Hence, $A$ is a relaxed $\eta$ - $\alpha$-monotone mapping. Now by defining the different function $f$ we find the solution set $\Omega$ of (6). First we compute, for $x=\left(x_{1}, x_{2}\right), y=\left(y_{1}, y_{2}\right) \in K$,

$$
\begin{aligned}
& \langle A x, \eta(y, x)\rangle+f(y)-f(x) \\
& =\left\langle A\left(x_{1}, x_{2}\right), \eta\left(\left(y_{1}, y_{2}\right),\left(x_{1}, x_{2}\right)\right)\right\rangle+f(y)-f(x) \\
& =\left\langle\left(x_{1}, x_{2}\right),\left(4\left(y_{1}-x_{1}\right), 4\left(y_{2}-x_{2}\right)\right)\right\rangle+f(y)-f(x) \\
& =4 x_{1}\left(y_{1}-x_{1}\right)+4 x_{2}\left(y_{2}-x_{2}\right)+f(y)-f(x) .
\end{aligned}
$$

(i) Let the function $f(x)=x_{1}+x_{2}$ for all $x=\left(x_{1}, x_{2}\right) \in$ $K$. It is easy to see that the solution set $\Omega=\{(0,0)\}$. That is, only when $x=(0,0),(6)$ holds for all $y \in K$.

(ii) Let the function $f(1,1)=-20$ and $f\left(x_{1}, x_{2}\right)=x_{1}+x_{2}$ for all $K \backslash\{(1,1)\}$. By (9), it is not hard to see that the solution set $\Omega=\{(0,0),(1,1)\}$.

(iii) Let the function $f\left(x_{1}, x_{2}\right)=-20$ for all $\left(x_{1}, x_{2}\right)=$ $(1 / n, 1 / n) \in K$ where $n \in \mathbb{N}$ and $f\left(x_{1}, x_{2}\right)=x_{1}+x_{2}$ for all $K \backslash\{(1 / n, 1 / n): n \in \mathbb{N}\}$. Then by (9) we see that $\Omega=\{(0,0),(1 / n, 1 / n): n \in \mathbb{N}\}$. In this case, $\Omega$ includes the unfinite elements.

Recently, Wang et al. [7] proposed the following equilibrium problem in a Hilbert space $H$ with a nonempty closed convex bounded subset $K$ : find $x \in K$ such that

$$
\Theta(x, y)+\langle T z, \eta(y, z)\rangle \geq 0, \quad \forall y \in K,
$$

where $T: K \rightarrow H$ is a relaxed $\eta$ - $\alpha$-monotone mapping. They introduced a new algorithm for solving the equilibrium problem in Hilbert spaces.

In [3], Fang and Huang did not give the algorithm to solve the variational inequality (6) or (7). In this paper, motivated and inspired by the above results, we introduced a new mixed equilibrium problem with the relaxed monotone mapping and prove the existence of solutions of the mixed equilibrium problem. Then we propose an iterative scheme to find the common element of the set of solutions of the mixed equilibrium problem and the set of fixed points of a quasi$\phi$-nonexpansive mapping in Banach spaces. In particular, the variational inequality (6) or (7) may be solved by the algorithm proposed in this paper. Our results extend and improve the corresponding ones given by Takahashi and Zembayashi [1], Fang and Huang [3], and Wang et al. [7]. 


\section{Preliminaries}

A Banach space $E$ is said to be strictly convex if $\|(x+y) / 2\|<$ 1 for all $x, y \in E$ with $\|x\|=\|y\|=1$ and $x \neq y$. It is said to be uniformly convex if $\lim _{n \rightarrow \infty}\left\|x_{n}-y_{n}\right\|=0$ for any two sequences $\left\{x_{n}\right\}$ and $\left\{y_{n}\right\}$ in $E$ such that $\left\|x_{n}\right\|=\left\|y_{n}\right\|=1$ and $\lim _{n \rightarrow \infty}\left\|\left(x_{n}+y_{n}\right) / 2\right\|=1$.

Let $U=\{x \in E:\|x\|=1\}$ be the unit sphere of $E$. A Banach space $E$ is said to be smooth provided

$$
\lim _{t \rightarrow 0} \frac{\|x+t y\|-\|x\|}{t}
$$

exists for each $x, y \in U$. It is said to be uniformly smooth if the limit is attained uniformly for $x, y \in E$.

Let $E^{*}$ be the topological dual space of $E$ and $J$ be the normalized duality mapping from $E$ into $2^{E^{*}}$ given by

$$
J x=\left\{x^{*} \in E^{*}:\left\langle x, x^{*}\right\rangle=\|x\|\left\|x^{*}\right\|,\left\|x^{*}\right\|=\|x\|\right\}, \quad \forall x \in E .
$$

It is well known that if $E$ is uniformly convex, then $J$ is uniformly continuous on bounded subsets of $E$ and if $E$ is uniformly smooth, then $E^{*}$ is uniformly convex.

Recently, Alber [8] introduced a generalized projection operator $\Pi_{K}$ in a Banach space $E$ with a nonempty closed convex subset $K$, which is an analogue of the metric projection in Hilbert spaces:

let $\phi: E \times E \rightarrow \mathbb{R}$ be a function defined by

$$
\phi(x, y)=\|x\|^{2}-2\langle x, J y\rangle+\|y\|^{2}, \quad \forall x, y \in E .
$$

The generalized projection $\Pi_{K}: E \rightarrow K$ is a mapping that assigns to an arbitrary point $x \in E$ the minimum point of the functional $\phi(x, y)$; that is, $\Pi_{K} x=\widehat{x}$, where $\widehat{x}$ is a solution to the minimization problem

$$
\phi(\widehat{x}, x)=\inf _{y \in K} \phi(y, x) .
$$

The existence and uniqueness of $\Pi_{K}$ follows from the properties of the function $\phi(x, y)$ and the strict monotonicity of the mapping $J$ (see, e.g., $[8-12]$ ).

Let $E$ be a smooth, strictly convex, and reflexive Banach space $E$. Then, for all $x, y \in E$, we have the following $[8,9,11]$ :

$$
\begin{gathered}
(\|y\|-\|x\|)^{2} \leq \phi(y, x) \leq(\|y\|+\|x\|)^{2}, \\
\phi(x, y)=0 \Longleftrightarrow x=y .
\end{gathered}
$$

Let $T$ be a mapping from $K$ into itself. A point $p \in K$ is said to be an asymptotic fixed point of $T$ [13] if $K$ contains a sequence $\left\{x_{n}\right\}$ which converges weakly to $p$ such that

$$
\lim _{n \rightarrow \infty}\left\|x_{n}-T x_{n}\right\|=0 \text {. }
$$

The set of asymptotic fixed points of $T$ is denoted by $\widehat{F}(T)$. The mapping $T$ is said to be relatively nonexpansive [14-16] if

$$
\begin{aligned}
\widehat{F}(T)=F(T), & \phi(p, T x) \leq \phi(p, x), \\
& \forall x \in K, p \in F(T) .
\end{aligned}
$$

We recall that a mapping $T: K \rightarrow K$ is said to be nonexpansive if $\|T x-T y\| \leq\|x-y\|$ for all $x, y \in K, T$ is said to be $\phi$-nonexpansive if $\phi(T x, T y) \leq \phi(x, y)$ for all $x, y \in K$, and $T$ is said to be quasi- $\phi$-nonexpansive if

$$
F(T) \neq \emptyset, \quad \phi(p, T x) \leq \phi(p, x), \quad \forall x \in K, p \in F(T) \text {. }
$$

Notice that the class of quasi- $\phi$-nonexpansive mappings is more general than the class of relatively nonexpansive mappings [14-16] which requires the strong restriction that $\widehat{F}(T)=F(T)$. Some examples of quasi- $\phi$-nonexpansive mappings may be found in [2].

A mapping $S: E \rightarrow E$ is said to be closed if for any sequence $\left\{x_{n}\right\} \subset E$ such that $\lim _{n \rightarrow \infty} x_{n}=x_{0}$ and $\lim _{n \rightarrow \infty} S x_{n}=y_{0}$, then $S x_{0}=y_{0}$.

The following lemmas are needed for the proof of our main results in next section.

Lemma 2 (see [10]). Let $E$ be a uniformly convex and smooth Banach space and let $\left\{x_{n}\right\},\left\{y_{n}\right\}$ be two sequences of $E$. If $\phi\left(x_{n}, y_{n}\right) \rightarrow 0$ and either $\left\{x_{n}\right\}$ or $\left\{y_{n}\right\}$ is bounded, then $x_{n}-y_{n} \rightarrow 0$.

Lemma 3 (see [8]). Let $K$ be a nonempty closed convex subset of a smooth Banach space $E$ and $x \in E$. Then $x_{0}=\Pi_{K} x$ if and only if

$$
\left\langle x_{0}-y, J x-J x_{0}\right\rangle \geq 0, \quad \forall y \in K
$$

Lemma 4 (see [8]). Let $E$ be a reflexive, strictly convex, and smooth Banach space, let $K$ be a nonempty closed convex subset of $E$ and $x \in E$. Then

$$
\phi\left(y, \Pi_{K} x\right)+\phi\left(\Pi_{K} x, x\right) \leq \phi(y, x), \quad \forall y \in K .
$$

The following lemma is contained implicitly in Step 1 of Theorem 3.1 of [17].

Lemma 5 (see [17]). Let $E$ be a uniformly convex and smooth Banach space, let $K$ be a nonempty closed convex subset of $E$, and let $T$ be a closed quasi- $\phi$-nonexpansive mapping from $K$ into itself. Then $F(T)$ is a closed convex subset of $K$.

Lemma 6 (see [18]). Let $E$ be a uniformly convex Banach space and let $B_{r}(0)$ be a closed ball of $E$. Then there exists a continuous strictly increasing convex function $g:[0, \infty) \rightarrow[0, \infty)$ with $g(0)=0$ such that

$$
\|\lambda x+\mu y+\gamma z\|^{2} \leq \lambda\|x\|^{2}+\mu\|y\|^{2}+\gamma\|z\|^{2}-\lambda \mu g(\|x-y\|)
$$

for all $x, y, z \in B_{r}(0)$ and $\lambda, \mu, \gamma \in[0,1]$ with $\lambda+\mu+\gamma=1$.

\section{Main Results}

For our main results, we introduce some definitions and lemmas as follows. 
Definition 7 (see [3]). Let $E$ be a Banach space with the dual space $E^{*}$ and let $K$ be a nonempty subset of $E$. Let $A: K \rightarrow$ $E^{*}$ and $\eta: K \times K \rightarrow E$ be two mappings. The mapping $A: K \rightarrow E^{*}$ is said to be $\eta$-hemicontinuous if, for any fixed $x, y \in K$, the function $f:[0,1] \rightarrow(-\infty, \infty)$ defined by $f(t)=\langle A((1-t) x+t y), \eta(x, y)\rangle$ is continuous at $0^{+}$.

Definition 8. Let $E$ be a Banach space with the dual space $E^{*}$ and let $K$ be a nonempty subset of $E$. A mapping $F: K \rightarrow 2^{E}$ is called a KKM mapping if, for any $\left\{x_{1}, \ldots, x_{n}\right\} \subset K$,

$$
\overline{\mathrm{co}}\left\{x_{1}, \ldots, x_{n}\right\} \subset \bigcup_{i=1}^{n} F\left(x_{i}\right),
$$

where $2^{E}$ denotes the family of all the nonempty subsets of $E$.

Lemma 9 (see [19]). Let $M$ be a nonempty subset of a Hausdorff topological vector space $X$ and let $F: M \rightarrow 2^{X}$ be a KKM mapping. If $F(x)$ is closed in $X$ for all $x \in X$ in $K$ and compact for some $x \in K$, then $\cap_{x \in M} F(x) \neq \emptyset$.

Lemma 10. Let $E$ be a reflexive Banach space with the dual space $E^{*}$ and let $K$ be a nonempty closed convex subset of $E$. Let $A: K \rightarrow E^{*}$ be an $\eta$-hemicontinuous and relaxed $\eta-\alpha$ monotone mapping. Let $\Theta$ be a bifunction from $K \times K$ to $\mathbb{R}$ satisfying $(A 1)$ and $(A 4)$ and let $f$ be a proper convex function from $K \times K$ to $\mathbb{R} \cup\{+\infty\}$. Let $r>0$ and $z \in E$. Assume that

(i) $\eta(x, x)=0$ for all $x \in K$;

(ii) for any fixed $u, v \in K$, the mapping $x \mapsto\langle A v, \eta(x, u)\rangle$ is convex.

Then the following problems (23) and (24) are equivalent:

(I) find $x \in K$ such that

$$
\begin{array}{r}
\Theta(x, y)+\langle A x, \eta(y, x)\rangle+f(y)-f(x) \\
+\frac{1}{r}\langle y-x, J x-J z\rangle \geq 0, \quad \forall y \in K ;
\end{array}
$$

(II) find $x \in K$ such that

$$
\begin{aligned}
\Theta(x, y)+\langle A y, \eta(y, x)\rangle+f(y)-f(x) & \\
+ & \frac{1}{r}\langle y-x, J x-J z\rangle \geq \alpha(y-x), \quad \forall y \in K .
\end{aligned}
$$

Proof. Let $x \in K$ be a solution of the problem (23). Since $A$ is relaxed $\eta-\alpha$ monotone, we have

$$
\begin{aligned}
\Theta(x, y)+\langle A y, \eta(y, x)\rangle+f(y)-f(x) \\
+\frac{1}{r}\langle y-x, J x-J z\rangle \\
\geq \Theta(x, y)+\alpha(y-x)+f(y)-f(x) \\
\quad+\frac{1}{r}\langle y-x, J x-J z\rangle+\langle A x, \eta(y, x)\rangle \\
\geq \alpha(y-x), \quad \forall y \in K .
\end{aligned}
$$

Thus, $x \in K$ is a solution of the problem (24).
Conversely, let $x \in K$ be a solution of the problem (24) and let $y \in K$ be any point with $f(y)<\infty$. From (24), it follows that $f(x)<\infty$. Letting

$$
y_{t}=(1-t) x+t y, \quad \forall t \in(0,1),
$$

we have $y_{t} \in K$. Since $x \in K$ is a solution of the problem (24), it follows that

$$
\begin{gathered}
\Theta\left(x, y_{t}\right)+\left\langle A y_{t}, \eta\left(y_{t}, x\right)\right\rangle+f\left(y_{t}\right)-f(x) \\
+\frac{1}{r}\left\langle y_{t}-x, J x-J z\right\rangle \\
\geq \alpha\left(y_{t}-x\right)=t^{p} \alpha(y-x) .
\end{gathered}
$$

The convexity of $f$ and conditions (i), (ii), (A1), and (A4) imply that

$$
\begin{aligned}
& f\left(y_{t}\right)-f(x)=f((1-t) x+t y) \\
& -f(x) \leq t(f(y)-f(x)), \\
& \left\langle A y_{t}, \eta\left(y_{t}, x\right)\right\rangle \leq(1-t)\left\langle A y_{t}, \eta(x, x)\right\rangle \\
& +t\left\langle A y_{t}, \eta(y, x)\right\rangle \\
& =t\langle A(x+t(y-x)), \eta(y, x)\rangle, \\
& \Theta\left(x, y_{t}\right) \leq(1-t) \Theta(x, x)+t \Theta(x, y)=t \Theta(x, y) . \\
& \Theta(x, y)+\langle A(x+t(y-x)), \eta(y, x)\rangle \\
& +f(y)-f(x)+\frac{1}{r}\langle y-x, J x-J z\rangle \\
& \geq t^{p-1} \alpha(y-x), \quad \forall y \in K .
\end{aligned}
$$

Since $A$ is $\eta$-hemicontinuous and $p>1$, letting $t \rightarrow 0$ in (29), we get

$$
\begin{gathered}
\Theta(x, y)+\langle A x, \eta(y, x)\rangle+f(y)-f(x) \\
+\frac{1}{r}\langle y-x, J x-J z\rangle \geq 0
\end{gathered}
$$

for all $y \in K$ with $f(y)<\infty$. When $f(y)=+\infty$, the relation

$$
\begin{gathered}
\Theta(x, y)+\langle A x, \eta(y, x)\rangle+f(y)-f(x) \\
+\frac{1}{r}\langle y-x, J x-J z\rangle \geq 0
\end{gathered}
$$

is trivial. Therefore, $x \in K$ is also a solution of the problem (23). This completes the proof.

Lemma 11. Let $E$ be a reflexive Banach space with the dual space $E^{*}$ and let $K$ be a nonempty closed convex bounded subset of $E$. Let $A: K \rightarrow E^{*}$ be an $\eta$-hemicontinuous and relaxed $\eta$ - $\alpha$-monotone mapping, let $\Theta$ be a bifunction from $K \times K$ to $\mathbb{R}$ 
satisfying $(A 1)$ and $(A 4)$, and let $f$ be a proper convex function from $K \times K$ to $\mathbb{R} \cup\{+\infty\}$. Let $r>0$ and $z \in E$. Assume that

(i) $\eta(x, y)+\eta(y, x)=0$ for all $x, y \in K$;

(ii) for any fixed $u, v \in K$, the mapping $x \mapsto\langle A v, \eta(x, u)\rangle$ is convex and lower semicontinuous;

(iii) $\alpha: E \rightarrow \mathbb{R}$ is weakly lower semicontinuous; that is, for any net $\left\{x_{\beta}\right\},\left\{x_{\beta}\right\}$ converges to $x$ in $\sigma\left(E, E^{*}\right)$ implying that $\alpha(x) \leq \lim \inf \alpha\left(x_{\beta}\right)$.

Then the problem (23) is solvable.

Proof. Define two set-valued mappings $F, G: K \rightarrow 2^{E}$ as follows:

$$
\begin{aligned}
F(y)= & \{x \in K: \Theta(x, y)+\langle A x, \eta(y, x)\rangle+f(y)-f(x) \\
& \left.+\frac{1}{r}\langle y-x, J x-J z\rangle \geq 0\right\}, \quad \forall y \in K, \\
G(y)= & \{x \in K: \Theta(x, y)+\langle A y, \eta(y, x)\rangle+f(y)-f(x) \\
& \left.+\frac{1}{r}\langle y-x, J x-J z\rangle \geq \alpha(y-x)\right\}, \quad \forall y \in K,
\end{aligned}
$$

respectively.

Now, we claim that $F$ is a KKM mapping. If $F$ is not a KKM mapping, then there exist $\left\{y_{1}, \ldots, y_{n}\right\} \subset K$ and $t_{i}>0$, $i=1, \ldots, n$, such that

$$
\sum_{i=1}^{n} t_{i}=1, \quad y=\sum_{i=1}^{n} t_{i} y_{i} \notin \bigcup_{i=1}^{n} F\left(y_{i}\right) .
$$

By the definition of $F$, we have

$$
\begin{aligned}
\Theta\left(y, y_{i}\right)+\left\langle A y, \eta\left(y_{i}, y\right)\right\rangle+f\left(y_{i}\right)-f(y) \\
+\frac{1}{r}\left\langle y_{i}-y, J y-J z\right\rangle<0, \quad \forall i=1, \ldots, n .
\end{aligned}
$$

It follows that

$$
\begin{aligned}
0 & =\Theta(y, y) \\
& =\Theta\left(y, \sum_{i=1}^{n} t_{i} y_{i}\right)+\left\langle A y, \eta\left(\sum_{i=1}^{n} t_{i} y_{i}, y\right)\right\rangle \\
& \leq \sum_{i=1}^{n} t_{i} \Theta\left(y, y_{i}\right)+\sum_{i=1}^{n} t_{i}\left\langle A y, \eta\left(y_{i}, y\right)\right\rangle \\
& <\sum_{i=1}^{n} t_{i}\left(f(y)-f\left(y_{i}\right)+\frac{1}{r}\left\langle y-y_{i}, J y-J z\right\rangle\right) \\
& =f(y)-\sum_{i=1}^{n} t_{i} f\left(y_{i}\right) \leq f(y)-f(y) \\
& =0,
\end{aligned}
$$

which is a contradiction. This implies that $F$ is a KKM mapping.
Now, we prove that

$$
F(y) \subset G(y), \quad \forall y \in K .
$$

For any given $y \in K$, letting $x \in F(y)$, then

$$
\begin{gathered}
\Theta(x, y)+\langle A x, \eta(y, x)\rangle+f(y)-f(x) \\
+\frac{1}{r}\langle y-x, J x-J z\rangle \geq 0 .
\end{gathered}
$$

Since $A$ is relaxed $\eta$ - $\alpha$-monotone, we have

$$
\begin{aligned}
\Theta(x, y)+\langle A y, \eta(y, x)\rangle+f(y)-f(x) \\
+\frac{1}{r}\langle y-x, J x-J z\rangle \\
\geq \Theta(x, y)+\langle A x, \eta(y, x)\rangle+\alpha(y-x) \\
\quad+f(y)-f(x)+\frac{1}{r}\langle y-x, J x-J z\rangle \\
\geq \alpha(y-x),
\end{aligned}
$$

which implies that $x \in G(y)$ and so

$$
F(y) \subset G(y), \quad \forall y \in K .
$$

As in the proof of Theorem 2.2 in [3], also, we can obtain

$$
\bigcap_{y \in K} F(y)=\bigcap_{y \in K} G(y) \neq \emptyset .
$$

Hence, there exists $x \in K$ such that

$$
\begin{aligned}
\Theta(x, y)+\langle A x, \eta(y, x)\rangle+f(y)-f(x) \\
+\frac{1}{r}\langle y-x, J x-J z\rangle \geq 0, \quad \forall y \in K .
\end{aligned}
$$

This completes the proof.

Next, let us denote the set of solutions of the following mixed equilibrium problem by $\operatorname{EP}(\Theta, A)$ : find $x \in K$ such that

$$
\Theta(x, y)+\langle A x, \eta(y, x)\rangle+f(y)-f(x) \geq 0, \quad \forall y \in K .
$$

It is easy to see that if $\Theta(x, y) \equiv 0$ for all $x, y \in K$, then the above mixed equilibrium problem reduces to the variational inequality problem (6) or (7).

Lemma 12. Let $E$ be a uniformly smooth, strictly convex Banach space with the dual space $E^{*}$ and let $K$ be a nonempty closed convex bounded subset of E. Let $A: K \rightarrow E^{*}$ be an $\eta$ hemicontinuous and relaxed $\eta$ - $\alpha$-monotone mapping, let $\Theta$ be a bifunction from $K \times K$ to $\mathbb{R}$ satisfying (A1), (A2), and (A4), and let $f$ be a proper convex function from $K \times K$ to $\mathbb{R} \cup\{+\infty\}$. Let $r>0$ and define a mapping $T_{r}: E \rightarrow K$ as follows:

$$
\begin{gathered}
T_{r}(x)=\{z \in K: \Theta(z, y)+\langle A z, \eta(y, z)\rangle+f(y)-f(z) \\
\left.+\frac{1}{r}\langle y-z, J z-J x\rangle \geq 0, \forall y \in K\right\}
\end{gathered}
$$


for all $x \in E$. Assume that

(i) $\eta(x, y)+\eta(y, x)=0$, for all $x, y \in K$;

(ii) for any fixed $u, v \in K$, the mapping $x \mapsto\langle A v, \eta(x, u)\rangle$ is convex and lower semicontinuous;

(iii) $\alpha: E \rightarrow \mathbb{R}$ is weakly lower semicontinuous; that is, for any net $\left\{x_{\beta}\right\}, x_{\beta}$ converges to $x$ in $\sigma\left(E, E^{*}\right)$ implying that $\alpha(x) \leq \liminf \alpha\left(x_{\beta}\right)$;

(iv) for any $x, y \in K, \alpha(x-y)+\alpha(y-x) \geq 0$;

(v) $\left\langle A\left(t z_{1}+(1-t) z_{2}\right), \eta\left(y, t z_{1}+(1-t) z_{2}\right)\right\rangle \geq$ $t\left\langle A z_{1}, \eta\left(y, z_{1}\right)\right\rangle+(1-t)\left\langle A z_{2}, \eta\left(y, z_{2}\right)\right\rangle$, for any $z_{1}, z_{2}, y \in K$ and $t \in[0,1]$.

Then the following hold:

(1) $T_{r}$ is single-valued;

(2) $T_{r}$ is a firmly nonexpansive-type mapping; that is, for all $x, y \in E$,

$\left\langle T_{r} x-T_{r} y, J T_{r} x-J T_{r} y\right\rangle \leq\left\langle T_{r} x-T_{r} y, J x-J y\right\rangle ;$

(3) $F\left(T_{r}\right)=\operatorname{EP}(\Theta, A)$;

(4) $T_{r}$ is quasi- $\phi$-nonexpansive satisfying $\phi\left(w, T_{r} x\right)+$ $\phi\left(T_{r} x, x\right) \leq \phi(w, x)$ for all $w \in F\left(T_{r}\right)$ and $x \in E$;

(5) $\operatorname{EP}(\Theta, A)$ is closed and convex.

Proof. We claim that $T_{r}$ is single-valued. Indeed, for any $x \in$ $C$ and $r>0$, let $z_{1}, z_{2} \in T_{r} x$. Then we have

$$
\begin{gathered}
\Theta\left(z_{1}, z_{2}\right)+\left\langle A z_{1}, \eta\left(z_{2}, z_{1}\right)\right\rangle+f\left(z_{2}\right)-f\left(z_{1}\right) \\
+\frac{1}{r}\left\langle z_{2}-z_{1}, J z_{1}-J x\right\rangle \geq 0, \\
\Theta\left(z_{2}, z_{1}\right)+\left\langle A z_{2}, \eta\left(z_{1}, z_{2}\right)\right\rangle+f\left(z_{1}\right)-f\left(z_{2}\right) \\
+\frac{1}{r}\left\langle z_{1}-z_{2}, J z_{2}-J x\right\rangle \geq 0 .
\end{gathered}
$$

Adding the two inequalities, it follows from (i) that

$$
\begin{gathered}
\Theta\left(z_{1}, z_{2}\right)+\Theta\left(z_{2}, z_{1}\right)+\left\langle A z_{1}-A z_{2}, \eta\left(z_{2}, z_{1}\right)\right\rangle \\
+\frac{1}{r}\left\langle z_{1}-z_{2}, J z_{2}-J z_{1}\right\rangle \geq 0 .
\end{gathered}
$$

Thus, from (A2), we have

$$
\left\langle A z_{1}-A z_{2}, \eta\left(z_{2}, z_{1}\right)\right\rangle+\frac{1}{r}\left\langle z_{1}-z_{2}, J z_{2}-J z_{1}\right\rangle \geq 0 ;
$$

that is,

$$
\frac{1}{r}\left\langle z_{1}-z_{2}, J z_{2}-J z_{1}\right\rangle \geq\left\langle A z_{2}-A z_{1}, \eta\left(z_{2}, z_{1}\right)\right\rangle .
$$

Since $T$ is relaxed $\eta$ - $\alpha$-monotone and $r>0$, one has

$$
\left\langle z_{1}-z_{2}, J z_{2}-J z_{1}\right\rangle \geq r \alpha\left(z_{2}-z_{1}\right) \text {. }
$$

In (48), exchanging $z_{1}$ to $z_{2}$, we get

$$
\begin{aligned}
\frac{1}{r}\left\langle z_{2}-z_{1}, J z_{1}-J z_{2}\right\rangle & \geq\left\langle A z_{1}-A z_{2}, \eta\left(z_{1}, z_{2}\right)\right\rangle \\
& \geq \alpha\left(z_{1}-z_{2}\right) ;
\end{aligned}
$$

that is,

$$
\left\langle z_{1}-z_{2}, J z_{2}-J z_{1}\right\rangle \geq \operatorname{r\alpha }\left(z_{1}-z_{2}\right) .
$$

Thus, it follows from (49), (51), and (iv) that

$$
\left\langle z_{1}-z_{2}, J z_{2}-J z_{1}\right\rangle \geq 0 \text {. }
$$

Since $E$ is strictly convex, we have $z_{1}=z_{2}$.

Next, we claim that $T_{r}$ is a firmly nonexpansive-type mapping. Indeed, for any $x, y \in K$, we have

$$
\begin{aligned}
& \Theta\left(T_{r} x, T_{r} y\right)+\left\langle A T_{r} x, \eta\left(T_{r} y, T_{r} x\right)\right\rangle+f\left(T_{r} y\right)-f\left(T_{r} x\right) \\
& +\frac{1}{r}\left\langle T_{r} y-T_{r} x, J T_{r} x-J x\right\rangle \geq 0 \\
& \Theta\left(T_{r} y, T_{r} x\right)+\left\langle A T_{r} y, \eta\left(T_{r} x, T_{r} y\right)\right\rangle+f\left(T_{r} x\right)-f\left(T_{r} y\right) \\
& +\frac{1}{r}\left\langle T_{r} x-T_{r} y, J T_{r} y-J y\right\rangle \geq 0 .
\end{aligned}
$$

Adding the above two inequalities, by (i) and (A2), we get

$$
\begin{aligned}
& \left\langle A T_{r} x-A T_{r} y, \eta\left(T_{r} y, T_{r} x\right)\right\rangle \\
& \quad+\frac{1}{r}\left\langle T_{r} y-T_{r} x, J T_{r} x-J T_{r} y-J x+J y\right\rangle \geq 0 ;
\end{aligned}
$$

that is,

$$
\begin{array}{r}
\frac{1}{r}\left\langle T_{r} y-T_{r} x, J T_{r} x-J T_{r} y-J x+J y\right\rangle \\
\geq\left\langle A T_{r} y-A T_{r} x, \eta\left(T_{r} y, T_{r} x\right)\right\rangle .
\end{array}
$$

Repeating the process from (48) to (52), we can obtain

$$
\left\langle T_{r} y-T_{r} x, J T_{r} x-J T_{r} y-J x+J y\right\rangle \geq 0 .
$$

Therefore, we have

$$
\left\langle T_{r} x-T_{r} y, J T_{r} x-J T_{r} y\right\rangle \leq\left\langle T_{r} x-T_{r} y, J x-J y\right\rangle,
$$

which shows that $T_{r}$ is firmly nonexpansive.

Next, we claim that $F\left(T_{r}\right)=\operatorname{EP}(\Theta, A)$. Indeed, we have the following:

$$
\begin{aligned}
u \in F\left(T_{r}\right) \Longleftrightarrow & u=T_{r} u \\
\Longleftrightarrow & \Theta(u, y)+\langle A u, \eta(y, u)\rangle+f(y)-f(u) \\
& +\frac{1}{r}\langle y-u, J u-J u\rangle \geq 0, \quad \forall y \in K \\
\Longleftrightarrow & \Theta(u, y)+\langle A u, \eta(y, u)\rangle \\
& +f(y)-f(u) \geq 0, \quad \forall y \in K \\
\Longleftrightarrow & u \in \operatorname{EP}(\Theta, A) .
\end{aligned}
$$

Finally, we prove (4) and (5). Indeed, we can obtain (4) directly from Lemma 2.8 and Lemma 2.9 of [1]. Moreover, since $T_{r}$ is quasi- $\phi$-nonexpansive, one sees that $T_{r}$ is closed and convex from Lemma 5 . Therefore, $\operatorname{EP}(\Theta, A)$ is also closed and convex. This completes the proof. 
Remark 13. In (42), if $A(x) \equiv 0$ for all $x \in K$, then the equilibrium problem (42) is reduced to the equilibrium problem in [20] and if $\eta(y, x)=y-x$ for all $x, y \in K$, then then the equilibrium problem (42) is reduced to the equilibrium problem in [21].

In the following, we give the main result of this paper.

Theorem 14. Let $K$ be a nonempty closed convex bounded subset of a uniformly convex, uniformly smooth Banach space $E$ with the dual space $E^{*}$. Let $A: K \rightarrow E^{*}$ be an $\eta$ hemicontinuous and relaxed $\eta-\alpha$ monotone mapping, let $\Theta$ be a bifunction from $K \times K$ to $\mathbb{R}$ satisfying (A1)-(A4), and let $f$ be a proper convex and lower semicontinuous function from $K \times K$ to $\mathbb{R} \cup\{+\infty\}$. Let $S: E \rightarrow E$ be a closed quasi- $\phi$-nonexpansive mapping such that $F=F(S) \cap \operatorname{EP}(\Theta, A) \neq \emptyset$. Assume that the conditions $(i)-(v)$, Lemma 12, and the following condition hold:

(vi) for all $x, y, z, w \in K$,

$$
\limsup _{t \downarrow 0}\langle A z, \eta(x, t y+(1-t) w)\rangle \leq\langle A z, \eta(x, w)\rangle .
$$

Let $\left\{x_{n}\right\}$ be a sequence in $K$ generated by the following manner:

$$
\begin{gathered}
x_{1}=x \in K \text { chosen arbitrarily, } \\
y_{n}=J^{-1}\left(\alpha_{n} J x_{n}+\left(1-\alpha_{n}\right) J S x_{n}\right), \\
u_{n} \in K \text { such that } \Theta\left(u_{n}, y\right) \\
+\left\langle A u_{n}, \eta\left(y, u_{n}\right)\right\rangle+f(y)-f\left(u_{n}\right) \\
+\frac{1}{r_{n}}\left\langle y-u_{n}, J u_{n}-J y_{n}\right\rangle \geq 0, \quad \forall y \in K, \\
C_{n}=\left\{z \in K: \phi\left(z, u_{n}\right) \leq \phi\left(z, x_{n}\right)\right\}, \\
D_{n}=\bigcap_{i=1}^{n} C_{i}, \\
x_{n+1}=\prod_{D_{n}} x, \quad \forall n \geq 1,
\end{gathered}
$$

where $J$ is the duality mapping on $E,\left\{\alpha_{n}\right\} \subset(0,1)$ with $0<\liminf _{n \rightarrow \infty} \alpha_{n}\left(1-\alpha_{n}\right)$, and $\left\{r_{n}\right\} \subset(r, \infty)$ with $r>0$. Then the sequence $\left\{x_{n}\right\}$ generated by (52) converges strongly to $\Pi_{F} x$.

Proof. First, since the inequality $\phi\left(z, u_{n}\right) \leq \phi\left(z, x_{n}\right)$ is equivalent to the following:

$$
2\left(\left\langle z, J x_{n}\right\rangle-\left\langle z, J u_{n}\right\rangle\right) \leq\left\|x_{n}\right\|^{2}-\left\|u_{n}\right\|^{2},
$$

$C_{n}$ is closed and convex for all $n \geq 1$. It follows from the definition of $D_{n}$ that $D_{n}$ is also closed and convex for all $n \geq 1$.
On the other hand, since every $T_{r_{n}}$ is quasi- $\phi$-nonexpansive, according to Lemma 12 (4), we have, for any $w \in F$,

$$
\begin{aligned}
\phi\left(w, u_{n}\right)= & \phi\left(w, T_{r_{n}} y_{n}\right) \\
\leq & \phi\left(w, y_{n}\right) \\
= & \phi\left(w, J^{-1}\left(\alpha_{n} J x_{n}+\left(1-\alpha_{n}\right) J S x_{n}\right)\right) \\
= & \|w\|^{2}-2 \alpha_{n}\left\langle w J x_{n}\right\rangle-2\left(1-\alpha_{n}\right)\left\langle w, J S x_{n}\right\rangle \\
& +\left\|\alpha_{n} J x_{n}+\left(1-\alpha_{n}\right) J S x_{n}\right\|^{2} \\
\leq & \|w\|^{2}-2 \alpha_{n}\left\langle w J x_{n}\right\rangle-2\left(1-\alpha_{n}\right)\left\langle w, J S x_{n}\right\rangle \\
& +\alpha_{n}\left\|x_{n}\right\|^{2}+\left(1-\alpha_{n}\right)\left\|J S x_{n}\right\|^{2} \\
= & \alpha_{n} \phi\left(w, x_{n}\right)+\left(1-\alpha_{n}\right) \phi\left(w, S x_{n}\right) \\
\leq & \alpha_{n} \phi\left(w, x_{n}\right)+\left(1-\alpha_{n}\right) \phi\left(w, x_{n}\right) \\
= & \phi\left(w, x_{n}\right),
\end{aligned}
$$

which shows that $w \in C_{n}$ for all $n \geq 1$. This implies that $F \subset$ $C_{n}$ for all $n \geq 1$. The definition of $D_{n}$ shows that $F \subset D_{n}$ for all $n \geq 1$. Hence, the sequence $\left\{x_{n}\right\}$ generated by the algorithm (60) is well defined.

Note that $D_{n} \subset D_{n-1}$ for all $n \geq 1$. Hence, by $x_{n+1}=$ $\Pi_{D_{n}} x \in D_{n} \subset D_{n-1}$ and $x_{n}=\Pi_{D_{n-1}} x$, we have

$$
\phi\left(x_{n}, x\right) \leq \phi\left(x_{n+1}, x\right), \quad \forall n \geq 1 .
$$

Therefore, $\left\{\phi\left(x_{n}, x\right)\right\}$ is nondecreasing. Since $\left\{x_{n}\right\} \subset K$, $\left\{\phi\left(x_{n}, x\right)\right\}$ is bounded. It follows that the limit of $\left\{\phi\left(x_{n}, x\right)\right\}$ exists.

Let $m, n \in \mathbb{N}$ with $m>n$. Since $x_{m}=\Pi_{D_{m-1}} x \in D_{m-1} \subset$ $D_{n-1}$, from Lemma 4 it follows that

$$
\begin{aligned}
\phi\left(x_{m}, x_{n}\right)= & \phi\left(x_{m}, \Pi_{D_{n-1}} x\right) \leq \phi\left(x_{m}, x\right) \\
& -\phi\left(\Pi_{D_{n-1}} x, x\right)=\phi\left(x_{m}, x\right)-\phi\left(x_{n}, x\right) .
\end{aligned}
$$

Letting $n \rightarrow \infty$ in (64), it follows that $\phi\left(x_{m}, x_{n}\right) \rightarrow 0$. It follows from Lemma 2 that $\left\|x_{m}-x_{n}\right\| \rightarrow 0$ as $m, n \rightarrow \infty$. Hence $\left\{x_{n}\right\}$ is a Cauchy sequence. There exists a point $x^{*} \in K$ such that $x_{n} \rightarrow x^{*}$ as $n \rightarrow \infty$.

Next, we show that $x^{*} \in F(S)$. By taking $p=1$ in (64), one arrives at

$$
\lim _{n \rightarrow \infty} \phi\left(x_{n+1}, x_{n}\right)=0
$$

From Lemma 2, it follows that

$$
\lim _{n \rightarrow \infty}\left\|x_{n+1}-x_{n}\right\|=0 \text {. }
$$

Noticing that $x_{n+1} \in D_{n} \subset C_{n}$ for all $n \geq 1$, we obtain

$$
\phi\left(x_{n+1}, u_{n}\right) \leq \phi\left(x_{n+1}, x_{n}\right) \text {. }
$$


Thus, it follows from (65) that

$$
\lim _{n \rightarrow \infty} \phi\left(x_{n+1}, u_{n}\right)=0 .
$$

It follows from Lemma 2 that

$$
\lim _{n \rightarrow \infty}\left\|x_{n+1}-u_{n}\right\|=0 .
$$

Combining (66) with (69), one has

$$
\lim _{n \rightarrow \infty}\left\|x_{n}-u_{n}\right\|=0 .
$$

Since $x_{n} \rightarrow x^{*}$ as $n \rightarrow \infty$, we have

$$
u_{n} \longrightarrow x^{*} \quad(n \longrightarrow \infty) \text {. }
$$

On the other hand, since $J$ is uniformly norm-to-norm continuous on bounded sets, one has

$$
\lim _{n \rightarrow \infty}\left\|J x_{n}-J u_{n}\right\|=0 \text {. }
$$

Since $E$ is a uniformly smooth Banach space, one knows that $E^{*}$ is a uniformly convex Banach space. Let $r=$ $\sup _{n \geq 1}\left\{\left\|x_{n}\right\|,\left\|S x_{n}\right\|\right\}$. It follows from Lemma 6 that, for any $w \in F$,

$$
\begin{aligned}
\phi\left(w, u_{n}\right)= & \phi\left(w, T_{r_{n}} y_{n}\right) \\
\leq & \phi\left(w, y_{n}\right) \\
= & \phi\left(w, J^{-1}\left(\alpha_{n} J x_{n}+\left(1-\alpha_{n}\right) J S x_{n}\right)\right) \\
= & \|w\|^{2}-2 \alpha_{n}\left\langle w, J x_{n}\right\rangle-2\left(1-\alpha_{n}\right)\left\langle w, J S x_{n}\right\rangle \\
& +\left\|\alpha_{n} J x_{n}+\left(1-\alpha_{n}\right) J S x_{n}\right\|^{2} \\
\leq & \|w\|^{2}-2 \alpha_{n}\left\langle w, J x_{n}\right\rangle-2\left(1-\alpha_{n}\right)\left\langle w, J S x_{n}\right\rangle \\
& +\alpha_{n}\left\|J x_{n}\right\|^{2}+\left(1-\alpha_{n}\right)\left\|J S x_{n}\right\|^{2} \\
& -\alpha_{n}\left(1-\alpha_{n}\right) g\left(\left\|J S x_{n}-J x_{n}\right\|\right) \\
= & \alpha_{n} \phi\left(w, x_{n}\right)+\left(1-\alpha_{n}\right) \phi\left(w, S x_{n}\right) \\
& -\alpha_{n}\left(1-\alpha_{n}\right) g\left(\left\|J S x_{n}-J x_{n}\right\|\right) \\
\leq & \phi\left(w, x_{n}\right)-\alpha_{n}\left(1-\alpha_{n}\right) g\left(\left\|J S x_{n}-J x_{n}\right\|\right) .
\end{aligned}
$$

It follows that

$\alpha_{n}\left(1-\alpha_{n}\right) g\left(\left\|J S x_{n}-J x_{n}\right\|\right) \leq \phi\left(w, x_{n}\right)-\phi\left(w, u_{n}\right)$.

On the other hand, one has

$$
\begin{aligned}
\phi\left(w, x_{n}\right)-\phi\left(w, u_{n}\right)= & \left\|x_{n}\right\|^{2}-\left\|u_{n}\right\|^{2}-2\left\langle w, J x_{n}-J u_{n}\right\rangle \\
\leq & \left\|x_{n}-u_{n}\right\|\left(\left\|x_{n}\right\|+\left\|u_{n}\right\|\right) \\
& +2\|w\|\left\|J x_{n}-J u_{n}\right\| .
\end{aligned}
$$

Thus, it follows from (70) and (72) that

$$
\phi\left(w, x_{n}\right)-\phi\left(w, u_{n}\right) \longrightarrow 0 \quad \text { as } n \longrightarrow \infty .
$$

Noting that $0<\liminf _{n \rightarrow \infty} \alpha_{n}\left(1-\alpha_{n}\right)$ and using (74) and (76), we get

$$
g\left(\left\|J x_{n}-J S x_{n}\right\|\right) \longrightarrow 0 \quad(n \longrightarrow \infty) .
$$

It follows from the continuousness of $g$ that

$$
\left\|J x_{n}-J S x_{n}\right\| \longrightarrow 0 \quad(n \longrightarrow \infty) .
$$

Since $J^{-1}$ is also uniformly norm-to-norm continuous on bounded sets, one gets

$$
\lim _{n \rightarrow \infty}\left\|x_{n}-S x_{n}\right\|=0 .
$$

From the closeness of $S$, we can conclude that $x^{*} \in F(S)$.

Next, we show that $x^{*} \in \operatorname{EP}(\Theta, A)$. From (62), we arrived at

$$
\phi\left(w, y_{n}\right) \leq \phi\left(w, x_{n}\right)
$$

From $u_{n}=T_{r_{n}} y_{n}$ and Lemma 12 (4), one has

$$
\begin{aligned}
\phi\left(u_{n}, y_{n}\right) & =\phi\left(T_{r_{n}} y_{n}, y_{n}\right) \\
& \leq \phi\left(w, y_{n}\right)-\phi\left(w, T_{r_{n}} y_{n}\right) \\
& \leq \phi\left(w, x_{n}\right)-\phi\left(w, T_{r_{n}} y_{n}\right) \\
& =\phi\left(w, x_{n}\right)-\phi\left(w, u_{n}\right) .
\end{aligned}
$$

Thus, it follows from (76) that

$$
\phi\left(u_{n}, y_{n}\right) \longrightarrow 0 \quad(n \longrightarrow \infty) .
$$

From Lemma 2, we get

$$
\left\|u_{n}-y_{n}\right\| \longrightarrow 0 \quad(n \longrightarrow \infty) .
$$

Noting that $u_{n}=T_{r_{n}} y_{n}$, one obtains

$$
\begin{array}{r}
\Theta\left(u_{n}, y\right)+\left\langle A u_{n}, \eta\left(y, u_{n}\right)\right\rangle+f(y)-f\left(u_{n}\right) \\
+\frac{1}{r_{n}}\left\langle y-u_{n}, J u_{n}-J y_{n}\right\rangle \geq 0, \quad \forall y \in K .
\end{array}
$$

From (A4) and (i), it follows that

$$
\begin{array}{r}
\frac{1}{r_{n}}\left\|y-u_{n}\right\|\left\|J u_{n}-J y_{n}\right\| \\
\geq\left\langle A u_{n}, \eta\left(u_{n}, y\right)\right\rangle+f\left(u_{n}\right)-f(y)-\Theta\left(u_{n}, y\right) \\
\geq\left\langle A u_{n}, \eta\left(u_{n}, y\right)\right\rangle+f\left(u_{n}\right)-f(y)+\Theta\left(y, u_{n}\right), \\
\forall y \in K .
\end{array}
$$

Since $J$ is uniformly norm-to-norm continuous on bounded sets, one has

$$
\lim _{n \rightarrow \infty}\left\|J u_{n}-J y_{n}\right\|=0 .
$$


Noticing that $r_{n} \geq r>0$ for all $n \geq 1$, it follows from (A4), (ii), (85), and (86) that

$$
\begin{array}{r}
0 \geq\left\langle A x^{*}, \eta\left(x^{*}, y\right)\right\rangle+f\left(x^{*}\right)-f(y)+\Theta\left(y, x^{*}\right), \\
\forall y \in K .
\end{array}
$$

For all $0<t \leq 1$ and $y \in K$, define $y_{t}=t y+(1-t) x^{*}$. Noticing that $x^{*}, y \in K$, one obtains $y_{t} \in K$, which yields that

$$
0 \geq\left\langle A x^{*}, \eta\left(x^{*}, y_{t}\right)\right\rangle+f\left(x^{*}\right)-f\left(y_{t}\right)+\Theta\left(y_{t}, x^{*}\right) .
$$

It follows from (A1), (A4), (i), (ii), the convexity of $f$, and (88) that

$$
\begin{aligned}
0= & \Theta\left(y_{t}, y_{t}\right)+\left\langle A x^{*}, \eta\left(y_{t}, y_{t}\right)\right\rangle+f\left(y_{t}\right)-f\left(y_{t}\right) \\
\leq & t\left[\Theta\left(y_{t}, y\right)+\left\langle A x^{*}, \eta\left(y, y_{t}\right)\right\rangle+f(y)-f\left(y_{t}\right)\right] \\
& +(1-t)\left[\Theta\left(y_{t}, x^{*}\right)+\left\langle A x^{*}, \eta\left(p, y_{t}\right)\right\rangle\right. \\
& \left.+f\left(x^{*}\right)-f\left(y_{t}\right)\right] \\
\leq & t\left[\Theta\left(y_{t}, y\right)+\left\langle A x^{*}, \eta\left(y, y_{t}\right)\right\rangle+f(y)-f\left(y_{t}\right)\right]
\end{aligned}
$$

that is,

$$
\Theta\left(y_{t}, y\right)+\left\langle A x^{*}, \eta\left(y, y_{t}\right)\right\rangle+f(y)-f\left(y_{t}\right) \geq 0
$$

Letting $t \downarrow 0$, it follows from (A3), (vi), and the lower semicontinuity of $f$ that

$$
\begin{array}{r}
\Theta\left(x^{*}, y\right)+\left\langle A x^{*}, \eta\left(y, x^{*}\right)\right\rangle+f(y)-f\left(x^{*}\right) \geq 0, \\
\forall y \in K .
\end{array}
$$

This implies that $x^{*} \in \mathrm{EP}(\Theta, A)$. that

Finally, we prove $x^{*}=\Pi_{F} x$. From $x_{n+1}=\Pi_{D_{n}} x$, we see

$$
\left\langle x_{n+1}-z, J x-J x_{n+1}\right\rangle \geq 0, \quad \forall z \in D_{n} .
$$

Since $F \subset D_{n}$ for each $n \geq 1$, we have

$$
\left\langle x_{n+1}-w, J x-J x_{n+1}\right\rangle \geq 0, \quad \forall w \in F .
$$

By taking the limit in (93), one has

$$
\left\langle x^{*}-w, J x-J x^{*}\right\rangle \geq 0, \quad \forall w \in F .
$$

At this point, in view of Lemma 3, one sees that $x^{*}=\Pi_{F} x$. This completes the proof.

If $\Theta \equiv 0$ in Theorem 14 , then we have the following result.

Corollary 15. Let $K$ be a nonempty closed convex bounded subset of a uniformly convex, uniformly smooth Banach space $E$ with the dual space $E^{*}$. Let $A: K \rightarrow E^{*}$ be an $\eta$ hemicontinuous and relaxed $\eta$ - $\alpha$-monotone mapping and let $f$ be a proper convex and lower semicontinuous function from
$K \times K$ to $\mathbb{R} \cup\{+\infty\}$. Let $S: E \rightarrow E$ be a closed quasi- $\phi-$ nonexpansive mapping such that $F=F(S) \cap \Omega \neq \emptyset$. Assume that the conditions $(i)-(v)$, Lemma 12, and the following condition hold:

(vi) for all $x, y, z, p \in K$,

$$
\limsup _{t \downarrow 0}\langle A z, \eta(x, t y+(1-t) p)\rangle \leq\langle A z, \eta(x, p)\rangle .
$$

Let $\left\{x_{n}\right\}$ be a sequence in $K$ generated by the following manner:

$$
\begin{gathered}
x_{1}=x \in K \text { chosen arbitrarily, } \\
y_{n}=J^{-1}\left(\alpha_{n} J x_{n}+\left(1-\alpha_{n}\right) J S x_{n}\right), \\
u_{n} \in K \text { such that }\left\langle A u_{n}, \eta\left(y, u_{n}\right)\right\rangle+f(y)-f\left(u_{n}\right) \geq 0, \\
\quad \forall y \in K, \\
C_{n}=\left\{z \in K: \phi\left(z, u_{n}\right) \leq \phi\left(z, x_{n}\right)\right\}, \\
D_{n}=\bigcap_{i=1}^{n} C_{i}, \\
x_{n+1}=\prod_{D_{n}} x, \quad \forall n \geq 1,
\end{gathered}
$$

where $J$ is the duality mapping on $E,\left\{\alpha_{n}\right\} \subset(0,1)$ with $0<$ $\liminf _{n \rightarrow \infty} \alpha_{n}\left(1-\alpha_{n}\right)$, and $\left\{r_{n}\right\} \subset(r, \infty)$ with $r>0$. Then the sequence $\left\{x_{n}\right\}$ generated by (96) converges strongly to $\Pi_{F} x$.

If $A \equiv 0$ and $f \equiv 0$ in Theorem 14, then we have following.

Corollary 16. Let $K$ be a nonempty closed convex subset of a uniformly convex, uniformly smooth Banach space $E$ with the dual space $E^{*}$. Let $\Theta$ be a bifunction from $K \times K$ to $\mathbb{R}$ satisfying (A1)-(A4) and let $S: E \rightarrow E$ be a closed quasi$\phi$-nonexpansive mapping such that $F=F(S) \cap \operatorname{EP}(\Theta) \neq \emptyset$. Let $\left\{x_{n}\right\}$ be a sequence generated by the following manner:

$$
\begin{gathered}
x_{1}=x \in E \text { chosen arbitrarily, } \\
y_{n}=J^{-1}\left(\alpha_{n} J x_{n}+\left(1-\alpha_{n}\right) J S x_{n}\right),
\end{gathered}
$$$$
u_{n} \in K \text { such that } \Theta\left(u_{n}, y\right)
$$$$
+\frac{1}{r_{n}}\left\langle y-u_{n}, J u_{n}-J y_{n}\right\rangle \geq 0, \quad \forall y \in K,
$$

$$
C_{n}=\left\{z \in E: \phi\left(z, u_{n}\right) \leq \phi\left(z, x_{n}\right)\right\} \text {, }
$$

$$
D_{n}=\bigcap_{i=1}^{n} C_{i} \text {, }
$$

$$
x_{n+1}=\Pi_{D_{n}} x, \quad \forall n \geq 1 \text {, }
$$

where $J$ is the duality mapping on $E,\left\{\alpha_{n}\right\} \subset(0,1)$ with $0<$ $\liminf _{n \rightarrow \infty} \alpha_{n} \leq \limsup _{n \rightarrow \infty} \alpha_{n}<1$ and $\left\{r_{n}\right\} \subset(r, \infty)$ with $r>0$. Then the sequence $\left\{x_{n}\right\}$ generated by (97) converges strongly to $\Pi_{F} x$. 
Remark 17. Theorem 14 improves the corresponding ones of Wang et al. [7] from Hilbert spaces to Banach spaces and those of Takahashi and Zembayashi [1] from relative nonexpansive mapping to quasi- $\phi$-nonexpansive mapping.

\section{Conflict of Interests}

The authors declare that they have no conflict of interests.

\section{Authors' Contribution}

The authors read and approved the final paper.

\section{Acknowledgments}

This work is supported by the Scientific Research Fund of Hebei Provincial Education Department (Grant no.: Z2013110), the Society Program Fund of Hebei Provincial Education Department (Grant no.: GH132068), and the Fundamental Research Fund for the Central Universities (Grant no.: 13MS109).

\section{References}

[1] W. Takahashi and K. Zembayashi, "Strong and weak convergence theorems for equilibrium problems and relatively nonexpansive mappings in Banach spaces," Nonlinear Analysis, Theory, Methods and Applications, vol. 70, no. 1, pp. 45-57, 2009.

[2] X. L. Qin, Y. J. Cho, and S. M. Kang, "Convergence theorems of common elements for equilibrium problems and fixed point problems in Banach spaces," Journal of Computational and Applied Mathematics, vol. 225, no. 1, pp. 20-30, 2009.

[3] Y. P. Fang and N. J. Huang, "Variational-like inequalities with generalized monotone mappings in Banach spaces," Journal of Optimization Theory and Applications, vol. 118, no. 2, pp. 327338, 2003.

[4] D. Goeleven and D. Motreanu, "Eigenvalue and dynamic problems for variational and hemivariational inequalities," Communications on Applied Nonlinear Analysis, vol. 3, pp. 1-21, 1996.

[5] A. H. Saddqi, Q. H. Ansari, and K. R. Kazmi, "On nonlinear variational inequalities," Indian Journal of Pure and Applied Mathematics, vol. 25, pp. 969-973, 1994.

[6] R. U. Verma, "Nonlinear variational inequalities on convex subsets of banach spaces," Applied Mathematics Letters, vol. 10, no. 4 , pp. 25-27, 1997.

[7] S. H. Wang, G. Marino, and F. H. Wang, "Strong convergence theorems for a generalized equilibrium problem with a relaxed monotone mapping and a countable family of nonexpansive mappings in a Hilbert space," Fixed Point Theory and Applications, vol. 2010, Article ID 230304, 22 pages, 2010.

[8] Y. L. Alber, "Metric and generalized projection operators in Banach spaces: properties and applications," in Theorem and Applications of Nonlinear Operators of Accretive and Monotone Type, A. G. Kartsatos, Ed., pp. 15-50, Marcel Dekker, New York, NY, USA, 1996.

[9] I. Cioranescu, Geometry of Banach Spaces, Duaity Mappings and Nonlinear Problems, Kluwer, Dordrecht, The Netherlands, 1990.
[10] S. Kamimura and W. Takahashi, "Strong convergence of a proximal-type algorithm in a Banach space," SIAM Journal on Optimization, vol. 13, no. 3, pp. 938-945, 2003.

[11] W. Takahashi, Nonlinear Functional Analysis, Yokohama, Kanagawa, Japan, 2000.

[12] Y. L. Alber and S. Guerre-Delabriere, "On the projection methods for fixed point problems," Analysis, vol. 21, pp. 17-39, 2001.

[13] S. Reich, "A weak convergence theorem for the alternating method with Bregman distance," in Theory and Applications of Nonlinear Operators of Accretive and Montone Type, A. G. Kartsatos, Ed., pp. 313-318, Marcel Dekker, New York, NY, USA, 1996.

[14] D. Butnariu, S. Reich, and A. J. Zaslavski, "Asymptotic behavior of relatively nonexpansiv operators in Banach spaces," Journal of Applied Analysis, vol. 7, pp. 151-174, 2001.

[15] D. Butnariu, S. Reich, and A. J. Zaslavski, "Weak convergence of orbits of nonlinear operators in reflexive Banach spaces," Numerical Functional Analysis and Optimization, vol. 24, no. 56, pp. 489-508, 2003.

[16] Y. Censor and S. Reich, "Iterations of paracontractions and firmly nonexpansive operators with applications to feasibility and optimization," Optimization, vol. 37, no. 4, pp. 323-339, 1996.

[17] H. Y. Zhou and X. H. Gao, "A strong convergence theorem for a family of quasi- $\phi$-nonexpansive mappings in a banach space," Fixed Point Theory and Applications, vol. 2009, Article ID 351265, 12 pages, 2009.

[18] Y. J. Cho, H. Zhou, and G. Guo, "Weak and strong convergence theorems for three-step iterations with errors for asymptotically nonexpansive mappings," Computers and Mathematics with Applications, vol. 47, no. 4-5, pp. 707-717, 2004.

[19] K. Fan, "Some properties of convex sets related to fixed point theorems," Mathematische Annalen, vol. 266, no. 4, pp. 519-537, 1984.

[20] R. Wangkeeree and R. Wangkeeree, "A general iterative method for variational inequality problems, mixed equilibrium problems, and fixed point problems of strictly pseudocontractive mappings in Hilbert spaces," Fixed Point Theory and Applications, vol. 2009, Article ID 519065, 32 pages, 2009.

[21] S. Zhang, "Generalized mixed equilibrium problem in Banach spaces," Applied Mathematics and Mechanics, vol. 30, no. 9, pp. 1105-1112, 2009. 


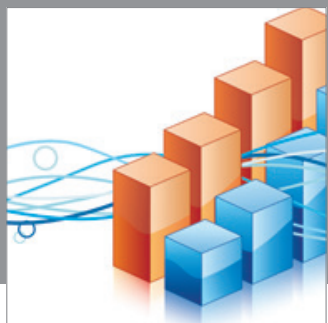

Advances in

Operations Research

mansans

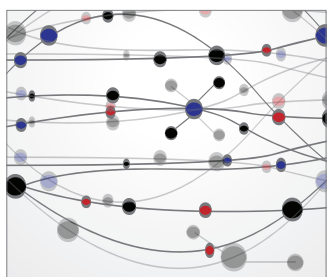

The Scientific World Journal
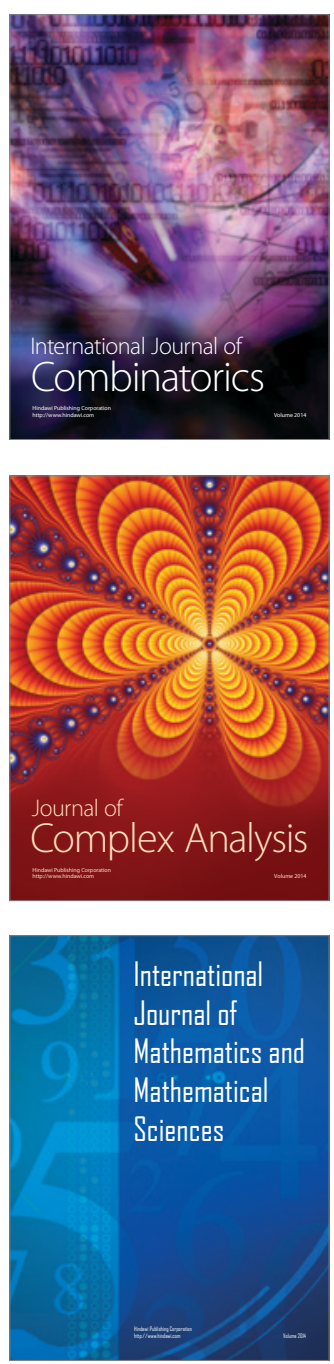
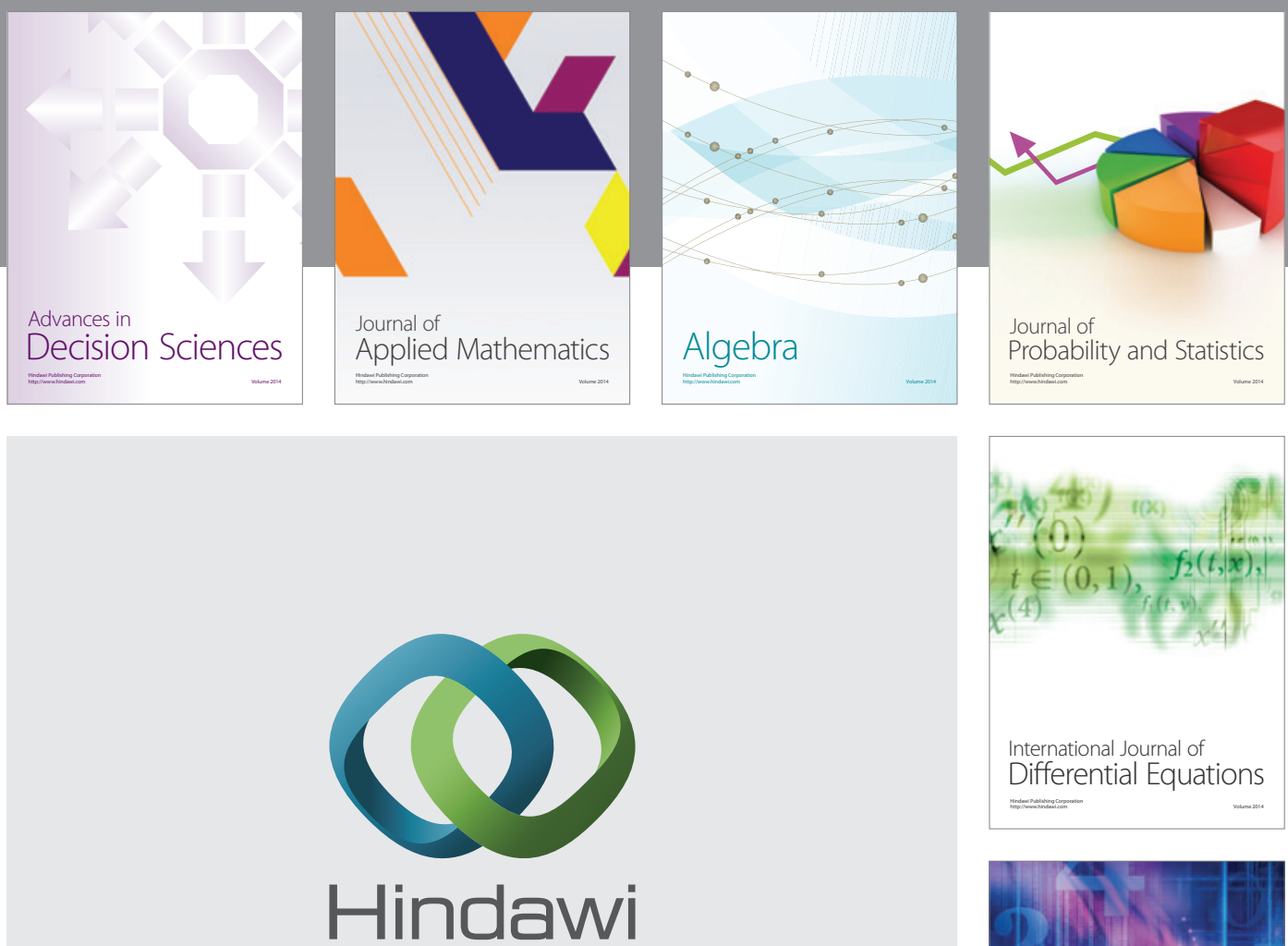

Submit your manuscripts at http://www.hindawi.com
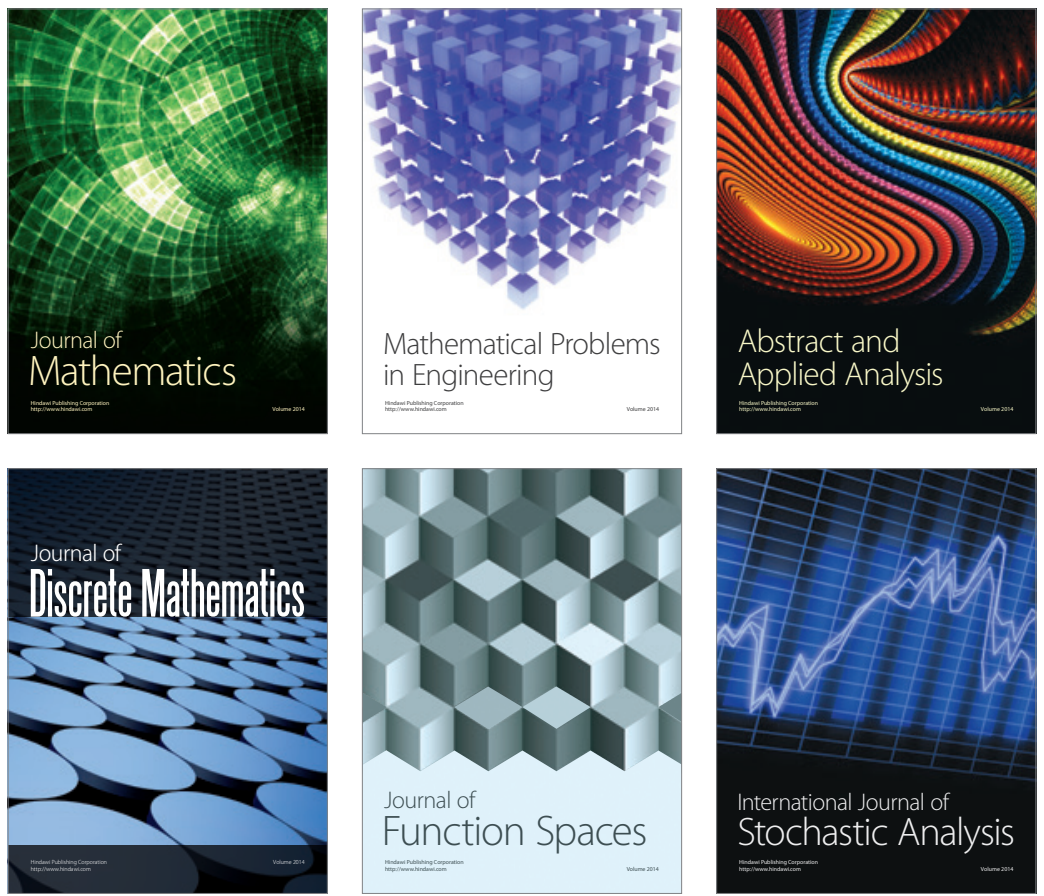

Journal of

Function Spaces

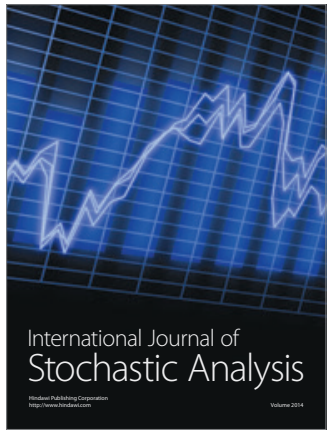

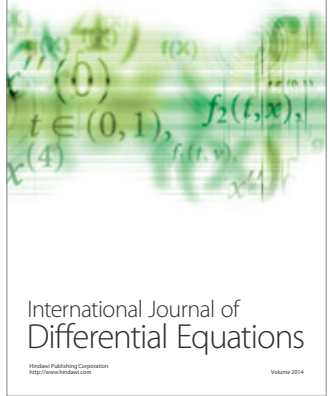
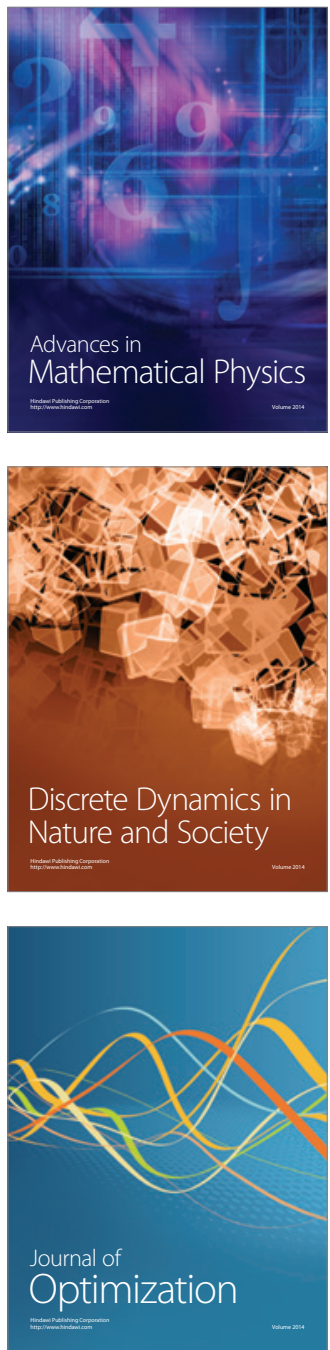